\title{
Developing and Evaluating an Instrument to Assess Perceptions of an Entry-level Physician Associate Doctoral Degree
}

\author{
Hyun-Jin Jun \\ University of Maryland, Baltimore \\ Karen Gordes \\ University of Maryland, Baltimore \\ Shani Fleming \\ University of Maryland, Baltimore \\ Violet Kulo \\ University of Maryland, Baltimore \\ James Cawley \\ University of Maryland, Baltimore \\ Gerald Kayingo ( $\sim$ gkayingo@umaryland.edu ) \\ University of Maryland, Baltimore
}

\section{Research Article}

Keywords: Health professions education, Measures, Instrument, Perceptions, Entry-level doctoral degree, Physician assistants/associates

Posted Date: February 9th, 2022

DOI: https://doi.org/10.21203/rs.3.rs-1318335/v1

License: @) (i) This work is licensed under a Creative Commons Attribution 4.0 International License. Read Full License 


\section{Abstract}

\section{Background}

Most health professions in the United States have adopted clinical or practice doctorates, sparking an ongoing debate on whether physician assistants/associates (PAs) should transition from a master's to a doctorate as the terminal degree. Although more studies are expected to be conducted, there is no validated instrument assessing perceptions of various stakeholders regarding an entry-level PA doctoral degree. The objective of this study was to develop and evaluate a novelself-report measure to assess perceptions of an entry-level PA doctoral degree.

\section{Methods}

A multifaceted, mixed-methods approach was adopted. Based on a comprehensive literature review regarding the impact of the doctoral transitions in health professions, an initial version of perceptions of an entry-level terminal PA doctoral degree scale (PEDDS) was generated. This scale was pilot tested with a group of PA faculty, students, and clinicians. Then, a crosssectional survey consisting of 67 items was conducted with a national random sample of 1,368 practicing PAs and PA students. Additionally, semi-structured interviews were conducted to ensure validity of PEDDS. A principal component analysis (PCA) was conducted to reduce the number of items and reveal the underlying structure of PEDDS.

\section{Results}

The PCA confirmed 10 factors of PEDDS consisting of 53 items as the best-fit factor structure with adequate internal consistency of subscales. Those factors include a) expected positive impact on the PA profession, b) expected impact on prerequisites, (c) expected impact on the student preparedness as PA faculty and educators, (d) expected impact on the student preparedness as clinicians, (e) expected impact on accreditation and certification, (f) expected impact on curriculum, (g) expected impact on PA educators, (h) expected positive impact on diversity, (i) expected negative impact on the PA profession, and (j) expected impact on the student competency.

\section{Conclusions}

The present study highlights the need to develop valid and reliable measurements to assess perceptions regarding the transition to the entry-level doctorate across health professions. This study could be used to guide further discussion of the entry-level doctorates for PAs and other health professions by bridging the gap of existing literature related to valid, reliable, and standardized measures on this topic.

\section{Background}

In the last two decades, there has been a growing trend toward entry-level doctoral degrees in various health professions in the United States (U.S.) [1, 2]. Entry-level clinical doctorates have been adopted in the fields of pharmacy, physical therapy, and advanced practice nursing [3-5]. To date, a master's degree is considered the terminal degree and the minimum entrylevel qualification in the physician assistant/associate (PA) profession, but there has been ongoing debate regarding an entry-level doctoral degree for PAs since mid-90's [6, 7]. In 2009, a formal PA Doctoral Summit was convened by national PA organizations (i.e., American Academy of PAs [AAPA], Physician Assistant Education Association [PAEA]) to discuss the future of doctoral education for PAs. After obtaining input from a wide range of stakeholders, summit participants recommended against an entry-level doctoral degree for PAs but encouraged PAs to explore various options for postprofessional training [8]. Over time, there have been growing interests and research exploring perceptions of various stakeholders regarding doctoral education for PAs. Using a randomized sample of 1,500 American PAs, Ohlemeier and Muma (2008) conducted a cross-sectional study investigating perceptions of the entry-level doctoral degree of practicing PAs and found that the majority of the respondents did not support moving toward an entry-level doctorate for the PA profession [9]. Similar findings were also reported in subsequent studies [10-14]. Consequently, the national PA organizations such as 
AAPA and PAEA have opposed several motions to adopt the entry-level terminal doctoral degree for PAs due to increased debt burden and potential adverse impact on the diversity of the workforce [15].

As the health care milieu continues to change, the quest for doctoral education for PAs has continued at various levels. As of 2022, about 11 institutions have established post-professional programs such as Doctor of Medical Science $[6,7,12,16,17]$. However, the value, risks, and benefits are still subject to discussion, and the PA entry-level doctoral credential debate continues. Recently a study sponsored by the PAEA investigated the potential risks and benefits of the entry-level doctoral degree for PAs. The results from this study were mixed, with some people advocating for the entry-level doctorate, whereas others were against it $[12,16]$. Similarly, the AAPA research commission has undertaken a study assessing current perceptions and give guidance to the professions [18]. In May 2021, the subject of the entry-level doctorate for PAs was amongst the hotly discussed topics in the House of Delegates. Taken together, the research and various discussions call for further investigation to guide future discussion of the entry-level doctorates for PAs. Over a dozen scholarly documents have been produced in the past year alone on this topic. As we expect that more studies will be conducted in this field, it is essential for researchers to have a reliable, valid, and replicable/reproducible instrument to conduct research on terminal doctoral degrees in health professions. To our knowledge, there is no existing validated instrument assessing perceptions of various stakeholders regarding an entry-level PA doctoral degree. This study aimed to develop and evaluate a novel selfreport measure to assess perceptions of an entry-level PA doctoral degree.

\section{Methods}

\section{Study procedures and participants}

A multifaceted, mixed-methods approach was used to develop and test an instrument to measure perceptions of an entrylevel PA doctoral degree (Figure 1). This study was approved by the Institutional Review Board (IRB) of the University of Maryland Baltimore. Informed consent was obtained from all participants.

\section{INSERT FIGURE 1 ABOUT HERE}

\section{Step 1: Literature review}

A comprehensive review of the existing literature, the ground of the instrument development, was completed to investigate the impact of the transitions of health professions doctoral programs including nursing, pharmacy, and physical therapy. Articles were searched in June 2020 through electronic databases including CINAHL (Cumulative Index to Nursing and Allied Health Literature), Cochrane Database of Systematic Reviews, Medline, and PubMed based on inclusion and exclusion criteria. We focused on exploring risk, benefits, outcomes for the doctoral transition, and related political and regulatory factors. Based on the literature review, research team members who have extensive experience in PA education identified overarching themes and key concepts to capture perceived benefits and risks of the doctoral transition. Those themes and concepts were evaluated for content validity and consistency by research team members, and any discrepancy was discussed until consensus was reached. Overarching themes included degree evolution, political and regulatory factors that promoted transition, and the impact of the transition on faculty, students, profession, and education curricula changes [6]. Key concepts within the overarching themes of perceived benefits and risks prior to their transition and impact after their transition were identified from this literature review and used to generate the questionnaires for both the quantitative survey and qualitative interviews.

\section{Step 2: Item development and online cross-sectional survey}

The perceptions of an entry-level $\underline{P} A \underline{\text { doctoral }}$ degree scale (PEDDS) have been developed for use in this cross-sectional survey. It is based primarily on the empirically derived set of constructs identified in prior research, which would capture the breadth of the potential impact of the doctoral transitions in health professions. The themes for PA-specific PEDDS include the benefits and risk, the impact on the PA profession/PA educator/clinical training sites/scope of practice, outcomes, and 
expected impact to students' preparedness/competency areas/curriculum/prerequisites. As a preliminary step, PEDDS was pilot tested with a group of PA faculty, students, and clinicians to achieve face validity and reliability of the instrument. Based on their recommendations, PEDDS was revised into 67 items using a five-point Likert scale to assess participant's selfreported perspectives on the risks, benefits, and impact of transitioning to an entry-level PA doctoral degree. A revised survey was distributed to a random sample of 1,368 practicing PAs and PA students across the U.S. in 2020 through Qualtrics, a web-based software/platform for creating and distributing online surveys. Study participants were recruited from AAPA's PA Observations Service and the Maryland Academy of Physician Assistants listserv. The results of power analysis using G*Power software package indicated the estimated sample size to be at least 74 or 160 subjects to obtain $95 \%$ chance of detecting large- $(d=.35)$ or medium-sized effect $(d=.15)$, respectively as significant at the 05 level [19]. A final sample included 636 subjects who completed the survey ( $46 \%$ response rate).

\section{Step 3: Semi-structured interviews}

We conducted semi-structured interviews with 38 key stakeholders to collect information on attitudes, opinions, and experiences related to entry-level health profession doctoral degrees. A purposive sampling was used to recruit interprofessional stakeholders, including clinical partners (i.e., practicing clinicians including PAs and Physician Practitioners), academic leaders (i.e., Deans, Provosts, Presidents across the health professions of medicine, nursing, pharmacy, and physical therapy), PA education community members (i.e., PA association leaders and members, PA program directors, PA faculty), and PA employers. Based on the findings from the interprofessional literature review, a semi-structured interview guide consisting of 11 items was developed to assess the feasibility, the benefits, and risks as well as the impact of an entry-level PA doctorate degree. First, the same eight open-ended questions were asked to all stakeholders (e.g., "what do you see are the benefits and risks of conferral of a doctorate degree for entry-level PAs?", "what do you foresee the impact of doctorate PA programs to be on the physician assistant profession? Do you anticipate changes in scope of practice? Impact on diversity of PA workforce? PA educators? Any new roles for physician assistant with an advanced degree?"). Then, three open-ended questions specific to each stakeholder group were asked (e.g., "how do you think your program would be affected should this transition occur?", "What institutional and faculty qualifications are needed to meet the demands of a doctorate program?"). The results of the semi-structured interviews were triangulated with the cross-sectional survey data to ensure content validity of PEDDS.

\section{Statistical analysis}

A principal component analysis (PCA) was conducted using SPSS version 28 for Windows [20] to reduce the number of items and reveal the underlying structure of PEDDS. Factorability of the 67 items were assessed through several preliminary tests related to the assumption checking. None of the assumptions for the PCA was violated. First, data were initially screened for missing data and univariate outliers across each item. There were no significant outliers and a few missing data across items. Missing data were handled using listwise deletion due to the low frequency of missing values (ranging from 0.2 to $0.9 \%)$. Second, the normality assumption was confirmed by assessing the skewness. Third, Pearson correlation coefficients indicated that each item was correlated at least to one other item with a linearity of variables, ranging from .08 to .79. Fourth, the Kaiser-Meyer-Olkin (KMO) measure for sampling adequacy was .97, indicating the sampling adequacy was excellent to run PCA (> .60) [21, 22]. Lastly, Bartlett's test of sphericity was significant $\left(\chi^{2}(2211)=29815.73, p<.001\right)$, indicating adequate correlations between variables to compress the data into a smaller number of components in a meaningful way [23]. For the main analysis, PCA was conducted with oblique (a direct oblimin) rotation techniques of the factor loading matrix, assuming factor to be correlated based on the literature [23]. Communalities ranged from .39 to .86, suggesting that there is common variance across all items. Factors with eigenvalues greater than 1 [24] and factor loadings with a cut-off point of .40 or above $[25,26]$ were retained.

\section{Results}


The sample characteristics of this study are presented in Table 1. The results of PCA are presented in Table 2. During item deduction, 14 items with a factor loading of less than .4 or inappropriate items were excluded. The 53 items with a primary factor loading of at least .4 or above were retained for the final version of PEDDS. Factorial validity assessed by the eigenvalues and scree plots yielded 10 factors of PEDDS as the best-fit factor structure, accounting for $66.2 \%$ of variance (Figure 2).

\section{INSERT Table 1 ABOUT HERE}

INSERT Table 2 ABOUT HERE

\section{INSERT FIGURE 2 ABOUT HERE}

Initial eigenvalues indicated that the first factor (11 items), expected positive impact on the PA profession, explained $32.4 \%$ of variance with an eigenvalue of 17.15. Example items loaded onto the first factor include: a) "An entry-level PA doctoral degree will have the following impact on the PA Profession - Enhance billing and reimbursement opportunities", b) "An entrylevel PA doctoral degree will have the following impact on PA scope of practice and outcomes - Promote PA practice autonomy", c) "An entry-level PA doctoral degree will have the following impact on PA scope of practice and outcomes Enable PAs to practice at the top of their license", d) "An entry-level PA doctoral degree will have the following impact on PA scope of practice and outcomes - Enhance billing and reimbursement opportunities", e) "An entry-level PA doctoral degree will have the following impact on the PA Profession - Advance public recognition", and f) "An entry-level PA doctoral degree will have the following impact on PA scope of practice and outcomes - Increase access, quality, cost-effective care". Excellent internal consistency for first factor items was found with this sample $(a=.96)$. Composite scores were created to explore the descriptive statistics (Table 3), indicating that higher scores for items in the first factor suggest more positive perceptions for the entry-level doctoral degree on the PA profession $(M=22.08, S D=12.20$, range $=0-42)$.

\section{INSERT Table 3 ABOUT HERE}

The second factor consisting of 5 items referred to expected impact on prerequisites, including the likelihood of the impact on prerequisites (i.e., GPA, GRE, prerequisites courses, prior clinical experience, entrance examination). The second factor accounted for $8.4 \%$ of variance with an eigenvalue of 4.4. Higher sum score of items in this scale indicate greater likelihood of being impacted on prerequisites with a transition to the doctoral degree $(M=6.53, S D=3.01$, range $=0-10)$. Good internal consistency for second factor items was found with this sample $(a=.81)$.

The remaining eight factors with eigenvalues over 1 collectively accounted for $25.4 \%$ of the variance. The third (5 items, $5.0 \%$ of variance) and the fourth factors (7 items, $4.3 \%$ of variance) assessed expected impact on the student preparedness as PA faculty and educators (academia/teaching skills, administration, program and policy development, research skills, leadership), and expected impact on the student preparedness as clinicians (e.g., clinical practice skills, patent-centered practice knowledge, the readiness for team-based and collaborative patient care), respectively. Both of these factors presented good internal consistency with this sample ( $a=.84$ for third and .93 for fourth factors). Expected impact on accreditation and certification $(M=4.59, S D=1.87$, range $=0-6)$ and curriculum $(M=24.16, S D=3.01$, range $=12-29)$ were presented in the fifth (3 items, $3.4 \%$ of variance) and sixth (4 items, $3.2 \%$ of variance) factors, respectively. The seventh (3 items, $2.7 \%$ of variance) and ninth (4 items, $2.3 \%$ of variance) factors assessed expected impact on PA educator $(M=9.00$, $S D=2.40$, range $=0-6)$ and expected negative impact on the $P A$ profession $(M=8.29, S D=2.45$, range $=1-12)$. Expected positive impact on diversity ( 5 items, $2.6 \%$ of variance) and student competency ( 6 items, $2.1 \%$ of variance) were assessed in the eighth $(M=4.05, S D=3.43$, range $=0-14)$ and $10^{\text {th }}(M=3.53, S D=2.28$, range $=0-6)$ factors. The overall internal consistency ranged from .51 to .96 . Except for the subscale of expected negative impact on the PA profession $(a=.51)$, the internal consistencies for all subscales with this sample were moderate or higher, ranging from .63 to .96 [27].

\section{Discussion}


The present study sought to examine the underlying structure of a novel self-report measure regarding perceptions of an entry-level PA doctoral degree using PCA, followed by oblimin rotation. We found that a 10 -factor solution accounted for over three-fifth of the variance, all those factors presented adequate internal consistency as separate subscales. The first factor composed of 11 items assessed expected positive impact on the PA profession, particularly in terms of amplifying billing and reimbursement opportunities, PA practice autonomy, optimal team practice [13], the competitive advantage, public recognition, scope of practice, access/quality/cost effective care, and patient satisfaction. Higher scores indicate greater perceptions regarding the positive impact of the entry-level doctorate on the PA profession. For the ninth factor, expected negative impact on the PA profession (4 items) has been identified, which addresses possibilities for increasing the cost of education, limiting flexibility working across various specialties, confusing the patients, and causing dysfunctional relationships between PAs and physicians. Four subscales assess educational aspects regarding the transition to the doctoral degree, such as expected impact on prerequisites (5 items), curriculum (4 items), accreditation and certification (3 items), and PA educators (3 items). Other factors focus on the student preparedness as PA faculty and educators (5 items), the student preparedness as clinicians (7 items), and the student competency (6 items). It is noteworthy that 5 -item expected positive impact on diversity subscale has been confirmed, which includes shifting practice settings to urban, rural or underserved locations and to primary care and increasing enrollment and demand. The internal consistencies for the subscales of PEDDS were moderate or higher, ranging from .63 to .96, notwithstanding the low Cronbach's alpha for the subscale of expected negative impact on the PA profession $(a=.51)$. The findings of the current study indicate that PEDDS would be a useful instrument to assess a wide range of perspectives or perceptions regarding the transition to the entry-level doctorate.

A body of research has been conducted to assess perceptions regarding an entry-level doctorate in various health professions in past decades. However, we are unaware of any similar measurement tool utilized in the field of health professions. Additionally, most of the studies have focused on a certain sample or group (e.g., students, program directors) in this area despite that a transition to the entry-level doctoral degree would have a wide range of impact to various stakeholders and aspects of the profession. For instance, Swanchak and colleagues (2011) conducted research to explore perceptions of transitioning the entry-level degree for PAs to a clinical doctorate with a sample of 1,996 PA students from 30 PA programs in 2009 with 15 items using a 5-point Likert scale. Despite high internal reliability of the items, no standardized or valid instrument was used in the study, and the study only focused on the students' perspectives [28]. Similarly, Menezes, Senkomago, and Coniglo (2015) investigated the attitudes of PA students toward a clinical doctorate and related impacts with 1,658 PA students from 53 PA programs in 2010 [29]. The survey instrument was pilot tested but not validated. Coplan, Richardson, and Stoehr (2009) conducted mixed-methods research to explore the opinions regarding an entry-level clinical doctorate among 152 PA program medical directors using a 16-item non-validated survey in 2009 [30]. Recently, a study conducted by Brown and colleagues in 2020 addressed the potential impact of an entry-level doctorate on PAs and PA faculty and programs among 712 PA educators using a 32-item survey that has not been validated [16]. Although Muma and colleagues (2011) included representative samples of physicians, PAs, and PA faculty to compare perceptions regarding the entry-level doctoral education, a non-validated instrument seemed to be used [14]. Similar issues with using non-validated instruments in this topic have been found in other health professions research such as nursing [31], pharmacy [32, 33], physical therapy [34], and occupational therapy [35]. Given the importance of this topic, this study highlights the need to develop valid and reliable measurements to assess the various perceptions regarding the transition to the entry-level doctorate across health professions, which supports the rationale of the current study.

To the best of our knowledge, PEDDS is the first quantitative self-report instrument to assess perceptions regarding the entrylevel PA doctoral degree. The PEDDS was key in this investigation which used a multi-prong, mixed-methods approach, involving interprofessional literature review, cross-sectional survey, and semi-structured interviews to capture stakeholders' views on and impact of transitioning to an entry-level PA doctorate. The survey instrument was beta tested, and recommendations were used to refine the survey prior to distribution to study participants. Using systematic approaches for the scale development, this study includes perspectives and insights of various stakeholders, indicating potential multifaceted impact pertaining to the transition to an entry-level doctorate. The strength of this study includes the large 
sample size using a probability sampling, which contributes to validating the results. This study could be used to guide further discussion of the entry-level doctorates for PAs and other health professions by bridging the gap of existing literature related to valid, reliable, and standardized measures in this topic.

Despite the significance and strengths of the present study, there are some limitations. This cross-sectional study was conducted by distributing the survey one time; hence, test-retest reliability has not been established. Future research should redistribute the survey to ensure the reliability of measures on repeated administration. The internal consistency of the subscale of expected negative impact on the PA profession was low, and this may be partly due to the small number of items in this subscale, which can bias internal consistency [36]. Based on a preliminary study of a novel measure developed in the present study, future research should conduct a confirmatory factor analysis (CFA) to validate factors structure of the constructs identified in this study. Although generalization to other countries is limited because the present study was conducted in the U.S. context, this study could be replicated by diversifying the professions and countries to produce an instrument that could be used in other contexts and with other professions.

\section{Conclusions}

A novel self-report measurement instrument of PEDDS was developed using a multi-prong, mixed-methods approach, involving interprofessional literature review, cross-sectional survey, and semi-structured interviews to capture stakeholders' views on the impact of transitioning to an entry-level PA doctorate. This study will be useful in guiding further discussion of the entry-level doctorates for PAs and other health professions by bridging the gap of existing literature related to valid, reliable, and standardized measures in this topic. This instrument has potential to be adopted by other health professions considering a shift to entry-level doctoral education.

\section{Abbreviations}

AAPA: American Academy of Physician Assistants; PA(s): Physician Assistant/Associate; PAEA: Physician Assistant Education Association; PEDDS: Perceptions of an Entry-level PA Doctoral Degree Scale; United States: U.S.; Principal component analysis: PCA

\section{Declarations}

Ethics approval and consent to participate

This study was approved by the University of Maryland, Baltimore Institutional Review Board. Reference number: HP00092383. Informed consent was obtained from all participants. All methods were carried out in accordance with relevant guidelines and regulations.

Consent for publication

Not applicable.

Availability of data and materials

The datasets used and/or analyzed during the current study are available from the corresponding author on reasonable request.

\section{Competing interests}

The authors declared that they have no competing interest.

Funding

Page $7 / 22$ 
This study was supported by external funding from the Physician Assistant Education Association (PAEA). PAEA did not have any role in design of the study and collection, analysis, and interpretation of data and in writing the manuscript.

\section{Author's contributions}

These authors contributed equally to this work: GK, JC, KG, SF, and VK contributed to the design of the research, the development of instrument, and the conduct/analysis of qualitative interviews. HJ developed the concept of this paper, performed the statistical analyses, and drafted the manuscript. All authors read and approved the final manuscript.

\section{Acknowledgments}

The authors express their appreciation to the Physician Assistant Education Association for funding the project "An Exploration into the PA Entry-Level Doctoral Degree: A Report to PAEA Board of Directors" (Principal Investigator: Shani Fleming, MPH, PA-C), the American Academy of Physician Assistants, and Noël Smith for assistance with the administration of the national quantitative survey.

\section{References}

1. Royeen C, Lavin MA. A contextual and logical analysis of the clinical doctorate for health practitioners: dilemma, delusion, or de facto?. Journal of Allied Health. 2007 Jul 1;36(2):101-106.

2. Seegmiller JG, Nasypany A, Kahanov L, Seegmiller JA, Baker R. Trends in doctoral education among healthcare professions: an integrative research review. Athletic Training Education Journal. 2015;10(1):47-56.

https://doi.org/10.4085/100147

3. American Association of Colleges of Nursing. AACN position statement on the practice doctorate in nursing. 2004. https://www.aacnnursing.org/News-Information/Position-Statements-White-Papers/Practice-Doctorate. Accessed 12 Jun 2020

4. Plack MM, Wong CK. The evolution of the doctorate of physical therapy: moving beyond the controversy. J Phys Ther Educ. 2002;16(1):48-59. https://doi.org/10.1097/00001416-200201000-00008.

5. Supapaan T, Low BY, Wongpoowarak P, Moolasarn S, Anderson C. A transition from the BPharm to the PharmD degree in five selected countries. Pharm Pract (Granada). 2019;17(3):1611-1619.

https://dx.doi.org/10.18549/pharmpract.2019.3.1611

6. Gordes KL, Fleming S, Kulo V, Cawley JF, Kibe L, Kayingo G. An Exploration into the Physician assistant entry-level doctoral degree: Lessons learned from across health professions. J Physician Assist Educ. 2022;33(1):1-10. doi: 10.1097/JPA.0000000000000411

7. Kibe L, Kayingo G, Cawley JF. Postprofessional PA doctorates: a new era. JAAPA. 2018;31(11):46-51. doi: 10.1097/01.JAA.0000545078.39838.78

8. Physician Assistant Education Association. Physician assistant clinical doctorate summit: final report and summary. J Physician Assist Educ. 2009;20(2):22-8.

9. Ohlemeier LS, Muma RD. Perceptions of US physician assistants regarding the entry-level doctoral degree in PA education. J Physician Assist Educ. 2008;19(2):10-7. https://doi.org/10.1097/01367895-200819020-00002.

10. Coplan B, Meyer JE. Physician Assistants-One Less Doctor (ate) in the House. JAMA. 2011;22;305(24):2571-2572. doi:10.1001/jama.2011.877

11. Coplan B, Richardson L, Stoehr JD. Physician Assistant Program Medical Directors' Opinions of an Entry-Level Physician Assistant Clinical Doctorate Degree. Journal of Physician Assistant Education (Physician Assistant Education Association). 2009;20(2);8-13. https://doi.org/10.1097/01367895-200920020-00003.

12. Kulo V, Fleming S, Gordes KL, Jun HJ, Cawley JF, Kayingo G. A physician assistant entry-level doctoral degree: more harm than good?. BMC Medical Education. 2021;21(1):1-2. https://doi.org/10.1186/s12909-021-02725-5 
13. Miller AA, Coplan B. Physician assistant doctorate: a ticket to autonomy? J Physician Assist Educ. 2017;28(Suppl 1):S33-37. https://doi.org/10.1097/JPA.0000000000000147

14. Muma RD, Smith B, Anderson N, Richardson M, Selzer E, White R. Perceptions of U.S. physicians regarding the entry-level doctoral degree in physician assistant education: a comparative study with physician assistants and PA faculty. J Allied Health. 2011;40(1):25-33.

15. American Academy of Physician Assistants. Policy on doctoral degrees. https://www.aapa.org/about/aapa-governanceleadership/house-of-delegates/policy-manual-papers-and-forms/. Accessed 29 Oct 2020

16. Brown D, Quincy B, Snyder J. Physician Assistant Education Community Assumptions About an Entry-level Doctoral Degree. J Physician Assist Educ. 2021;32(4):207-224. doi: 10.1097/JPA.0000000000000385

17. Miller AA, Coplan B. Assessing the Economics of an Entry-Level Physician Assistant Doctoral Degree. J Physician Assist Educ. 2022. doi: 10.1097/JPA.0000000000000400

18. Kibe L, Rizoolo D, Acker S, Harbert K, Sapre K, Pydah S, Collins B, Pace D, Smith D. Research into the entry-level doctorate across four healthcare professions: An annotated bibliography. American Academy of PAs. 2020.

https://www.aapa.org/download/72187/. Accessed 12 Jun 2021

19. Cohen J. Statistical power analysis for the behavioral sciences. Academic press; 2013.

20. IBM Corp. IBM SPSS Statistics for Windows, Version 27.0. Armonk, NY: IBM Corp; 2020.

21. Hair J, Black W, Babin BYA, Anderson R, Tatham R. Multivariate data analysis. A global perspective. Pearson Prentice Hall; 2010.

22. Tabachnick BG, Fidell LS, Ullman JB. Using multivariate statistics. Boston, MA: Pearson; 2007. p. 481-498

23. Worthington RL, Whittaker TA. Scale development research: A content analysis and recommendations for best practices. The counseling psychologist. 2006;34(6):806-838. https://doi.org/10.1177/0011000006288127

24. Kaiser HF. The application of electronic computers to factor analysis. Educational and psychological measurement. 1960;20(1):141-151.

25. Meyers LS, Gamst G, Guarino AJ. Applied multivariate research: Design and interpretation ( $3^{\text {rd }}$ ed.). Sage publications; 2016.

26. Stevens JP. Applied multivariate statistics for the social sciences. Routledge; 2012.

27. Cohen L, Manion L, Morrison K. Research methods in education ( $6^{\text {th }}$ ed). routledge; 2007.

28. Swanchak LE, Levine AM, Arscott KE, Golden MA. Physician assistant students' perceptions of an entry-level doctorate degree. Journal of Physician Assistant Education (Physician Assistant Education Association). 2011;22(1).

29. Menezes P, Senkomago V, Coniglio D. Physician assistant students' attitudes towards a clinical doctoral degree. The Journal of Physician Assistant Education. 2015;26(1):3-9.

30. Coplan B, Richardson L, Stoehr JD. Physician assistant program medical directors' opinions of an entry-level physician assistant clinical doctorate degree. J Physician Assist Educ. 2009;20(2):8-13. https://doi.org/10.1097/01367895200920020-00003.

31. Rhodes M. Using effects-based reasoning to examine the DNP as the single entry degree for advanced practice nursing. OJIN: The Online Journal of Issues in Nursing. 2011;16(3). doi: 10.3912/OJIN.Vol16No03PPT01

32. ACCP Educational Affairs Committee, 1985-86. Survey of members regarding the entry-level degree for the profession of pharmacy. Drug Intelligence \& Clinical Pharmacy. 1987;21(6):537-539.

33. Nathan KT, Conn K, Birnie CR. Assessing student perceptions of the Pharm. D. degree at a private tertiary medical university in India. Pharmacy Education. 2017;17(1):335-340.

34. Detweiler BA, Baird DA, Jensen GM, Threlkeld AJ. The post-professional doctorate of physical therapy: A survey of practicing physical therapists. Journal of Physical Therapy Education. 1999;13(1):44. doi: 10.1097/00001416199901000-00009 
35. McCombie RP. Attitudes of Occupational Therapists and Occupational Therapy Assistants Toward the Entry-Level Bachelor's Degree for OTAs. The Open Journal of Occupational Therapy. 2016;4(1):5. doi: 10.15453/2168-6408.1182

36. Emons WH, Sijtsma K, Meijer RR. On the consistency of individual classification using short scales. Psychological methods. 2007 Mar;12(1):105-120.

\section{Tables}

Table 1 Description of sample characteristics $(N=636)$ 


\begin{tabular}{|c|c|c|}
\hline & $n^{\mathrm{a}}$ & $\%$ \\
\hline \multicolumn{3}{|l|}{ Sex } \\
\hline Female & 433 & 68.5 \\
\hline Male & 199 & 31.5 \\
\hline \multicolumn{3}{|l|}{ Hispanic/Latinx } \\
\hline Yes & 47 & 7.4 \\
\hline No & 584 & 92.6 \\
\hline \multicolumn{3}{|l|}{ Race } \\
\hline White & 523 & 82.2 \\
\hline Black/African American & 39 & 6.1 \\
\hline American Indian/Alaska Native & 6 & 0.9 \\
\hline Asian & 41 & 6.4 \\
\hline Native Hawaiian/Pacific Islander & 2 & 0.3 \\
\hline Multiracial & 18 & 2.8 \\
\hline Others & 19 & 3.0 \\
\hline \multicolumn{3}{|l|}{ Educational attainment } \\
\hline Associate degree & 2 & .3 \\
\hline Bachelor's degree & 97 & 15.3 \\
\hline Master's degree & 475 & 74.9 \\
\hline Doctorate degree & 60 & 9.5 \\
\hline \multicolumn{3}{|l|}{ Occupation ${ }^{b}$} \\
\hline Student & 109 & 17.2 \\
\hline PA clinician & 524 & 82.8 \\
\hline \multicolumn{3}{|l|}{ Length of practice as PA } \\
\hline Current student & 107 & 16.9 \\
\hline$<5$ years & 172 & 27.1 \\
\hline $5-10$ years & 148 & 23.3 \\
\hline $11-25$ years & 169 & 26.7 \\
\hline$>25$ years & 37 & 5.8 \\
\hline Non-PA & 1 & .2 \\
\hline
\end{tabular}

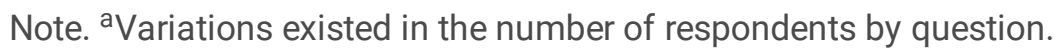

bSome of the PA clinicians reported additional professional roles such as faculty and administrators but they were all counted as PA clinicians. 
Table 2 Factor loadings and communalities from the principal components analysis in the PEDDS

Page 12/22 


\begin{tabular}{|c|c|c|c|c|c|c|c|c|c|c|c|c|}
\hline \multirow[t]{2}{*}{ Components } & \multirow[t]{2}{*}{ Item } & \multicolumn{10}{|c|}{ Factor } & \multirow[t]{2}{*}{ Communality } \\
\hline & & 1 & 2 & 3 & 4 & 5 & 6 & 7 & 8 & 9 & 10 & \\
\hline \multirow[t]{8}{*}{$\begin{array}{l}\text { Expected } \\
\text { positive } \\
\text { impact on } \\
\text { the PA } \\
\text { profession }\end{array}$} & $\begin{array}{l}\text { An entry-level PA } \\
\text { doctoral degree will } \\
\text { have the following } \\
\text { impact on the PA } \\
\text { Profession - } \\
\text { Enhance billing and } \\
\text { reimbursement } \\
\text { opportunities. }\end{array}$ & .87 & & & & & & & & & & .64 \\
\hline & $\begin{array}{l}\text { An entry-level PA } \\
\text { doctoral degree will } \\
\text { have the following } \\
\text { impact on PA scope } \\
\text { of practice and } \\
\text { outcomes - Promote } \\
\text { PA practice } \\
\text { Autonomy }\end{array}$ & .82 & & & & & & & & & & .71 \\
\hline & $\begin{array}{l}\text { An entry-level PA } \\
\text { doctoral degree will } \\
\text { have the following } \\
\text { impact on the PA } \\
\text { Profession - Enable } \\
\text { parity with other } \\
\text { professions. }\end{array}$ & .80 & & & & & & & & & & .71 \\
\hline & $\begin{array}{l}\text { An entry-level PA } \\
\text { doctoral degree will } \\
\text { have the following } \\
\text { impact on the PA } \\
\text { Profession - } \\
\text { Enhance the } \\
\text { competitive } \\
\text { advantage (edge). }\end{array}$ & .80 & & & & & & & & & & .78 \\
\hline & $\begin{array}{l}\text { An entry-level PA } \\
\text { doctoral degree will } \\
\text { have the following } \\
\text { impact on PA scope } \\
\text { of practice and } \\
\text { outcomes - Enhance } \\
\text { billing and } \\
\text { reimbursement } \\
\text { opportunities. }\end{array}$ & .80 & & & & & & & & & & .79 \\
\hline & $\begin{array}{l}\text { An entry-level PA } \\
\text { doctoral degree will } \\
\text { have the following } \\
\text { impact on PA scope } \\
\text { of practice and } \\
\text { outcomes - Enable } \\
\text { PAs to practice at } \\
\text { the top of their } \\
\text { license. }\end{array}$ & .79 & & & & & & & & & & .78 \\
\hline & $\begin{array}{l}\text { An entry-level PA } \\
\text { doctoral degree will } \\
\text { have the following } \\
\text { impact on the PA } \\
\text { Profession - } \\
\text { Advance public } \\
\text { recognition. }\end{array}$ & .75 & & & & & & & & & & .73 \\
\hline & $\begin{array}{l}\text { An entry-level PA } \\
\text { doctoral degree will } \\
\text { have the following }\end{array}$ & .65 & & & & & & & & & & .69 \\
\hline
\end{tabular}


impact on PA scope

of practice and

outcomes - Enhance

Optimal Team

Practice (OTP).

How likely an entry-

.64

level PA doctoral

degree will enhance

scope of practice.

An entry-level PA

doctoral degree will

have the following

impact on PA scope

of practice and

outcomes - Increase

access, quality, cost

effective care.

An entry-level PA

doctoral degree will

have the following

impact on PA scope

of practice and

outcomes - Increase

patient satisfaction.

Expected How likely will the

following

87

prerequisites prerequisites be

impacted if the PA

profession adopts

an entry-level PA

doctoral degree? -

GPA.

How likely will the

.77

following

prerequisites be

impacted if the PA

profession adopts

an entry-level PA

doctoral degree? -

GRE.

How likely will the

following

prerequisites be

impacted if the PA

profession adopts

an entry-level PA

doctoral degree? -

Pre-requisite

courses (statistics,

basic sciences).

How likely will the

following

prerequisites be

impacted if the PA

profession adopts

an entry-level PA

doctoral degree? -

Prior clinical

experience.

How likely will the

.65

following

prerequisites be

impacted if the PA 
profession adopts

an entry-level PA

doctoral degree? -

Entrance

examination (ie

PCAT).

Expected As compared to a

impact on

master's degree, I

believe an entry-

preparedness level PA doctoral

as PA faculty degree education

and will better prepare

educators students in the

following areas -

Academia/Teaching

skills.

As compared to a

master's degree, I

believe an entry-

level PA doctoral

degree education

will better prepare

students in the

following areas -

Administration.

As compared to a

master's degree, I

believe an entry-

level PA doctoral

degree education

will better prepare

students in the

following areas -

Program \& Policy

development.

As compared to a

master's degree, I

believe an entry-

level PA doctoral

degree education

will better prepare

students in the

following areas -

Research skills.

As compared to a master's degree, I

believe an entry-

level PA doctoral

degree education

will better prepare

students in the

following areas Leadership.

Expected As compared to a impact on master's degree, I

the student believe an entry-

preparedness level PA doctoral

as clinicians degree education

will better prepare

students in the

following areas -

Clinical practice

skills.

As compared to a 
master's degree, I believe an entrylevel PA doctoral degree education will better prepare students in the following areas The demands of working as a clinician.

As compared to a $-.75$

master's degree, I

believe an entry-

level PA doctoral

degree education

will better prepare.

students in the

following PA

competency areas -

Patient-centered

practice knowledge

(Medical

Knowledge).

As compared to a

master's degree, I

believe an entry-

level PA doctoral

degree education

will better prepare

students in the

following areas -

The readiness for

team based and

collaborative

patient care.

As compared to a $-.68$

(

believe an entry-

level PA doctoral

degree education

will better prepare

students in the

following areas -

Being up-to-date in

new or innovative

evidence-based

practice.

As compared to a

master's degree, I

believe an entry-

level PA doctoral

degree education

will better prepare

students in the

following areas -

Use of theory in

practice.

As compared to a

master's degree, I

believe an entry-

level PA doctoral

degree education

will better prepare

students in the

following PA 
competency areas -

Cultural humility.

$\begin{array}{ll}\text { Expected } & \text { How likely an entry- } \\ \text { impact on } & \text { level PA doctoral } \\ \text { accreditation } & \text { degree will - Change } \\ \text { and } & \text { the certification } \\ \text { certification } & \text { process. }\end{array}$

How likely an entry-

level PA doctoral

degree will - Change

the recertification

process.

How likely an entry-

level PA doctoral

.74

degree will - Change

accreditation

standards.

$\begin{array}{ll}\text { Expected } & \text { An entry-level PA } \\ \text { impact on } & \text { doctoral degree will } \\ \text { curriculum } & \text { have the following } \\ & \text { impact on } \\ & \text { curriculum - Require } \\ & \text { no additional } \\ & \text { content. }\end{array}$

An entry-level PA

doctoral degree will

have the following

impact on

curriculum - Require

new content.

An entry-level PA

doctoral degree will

have the following

impact on

curriculum - Require

significant change.

Some people

believe that the

current number of

credits, depth, and

breadth of PA

training offered in

most PA programs

to date are

sufficient for a

doctoral degree.

How strongly do

you agree or

disagree with this

statement?

Expected

impact on PA

educators
An entry-level PA

doctoral degree will

have the following

impact on PA

educators: - PA

educator

competencies will

change.

An entry-level PA

doctoral degree will

have the following

impact on PA 
educators: - PA

educator credentials

will change.

An entry-level PA

doctoral degree will

have the following

impact on PA

educators - PA

educator shortage

will worsen.

Expected How likely an entry-

positive

level PA doctoral

impact on degree will - Shift

diversity practice setting to

urban, rural or

underserved

locations.

How likely an entry-

.79

.62

level PA doctoral

degree will - Shift

practice setting to

primary care.

How likely an entry-

.66

.70

level PA doctoral

degree will -

Increase diversity.

An entry-level PA

doctoral degree will

have the following

impact on the PA

Profession -

Increase diversity.

An entry-level PA

doctoral degree will

have the following

impact on the PA

Profession -

Increase enrollment

and demand.

\section{Expected}

negative

impact on

the PA

profession
An entry-level PA

doctoral degree will

have the following

impact on the PA

Profession -

Increase the cost of

PA education.

An entry-level PA

doctoral degree will

have the following

impact on PA scope

of practice and

outcomes - Limit PA

flexibility working

across various

specialties.

How likely an entry-

.58

level PA doctoral

degree will -

Confuse the patient. 
negatively impact

the PA-Physician

relationship.

\section{Expected As compared to a \\ impact on master's degree, I \\ the student believe an entry- \\ competency level PA doctoral \\ degree education \\ will better prepare \\ students in the \\ following PA \\ competency areas - \\ Professional and \\ legal aspects of \\ health care.}

As compared to a

master's degree, I

believe an entry-

level PA doctoral

degree education

will better prepare

students in the

following PA

competency areas -

Health care finance

and systems.

As compared to a

master's degree, I

believe an entry-

level PA doctoral

degree education

will better prepare

students in the

following PA

competency areas -

Society and

population health.

As compared to a

master's degree, I

believe an entry-

level PA doctoral

degree education

will better prepare

students in the

following PA

competency areas -

Health literacy and

communication.

As compared to a

master's degree, I

believe an entry-

level PA doctoral

degree education

will better prepare

students in the

following PA

competency areas -

Interprofessional

collaborative

practice and

leadership.

As compared to a

master's degree, I

believe an entry-

level PA doctoral 
degree education

will better prepare

students in the

following PA

competency areas -

Ongoing

Professional

development.

Table 3 Descriptive statistics for PEDDS

\begin{tabular}{|c|c|c|c|c|c|}
\hline Subscale & $\begin{array}{l}\text { Number of } \\
\text { items }\end{array}$ & $\mathrm{M}(\mathrm{SD})$ & Skewness & Kurtosis & $\begin{array}{l}\text { Cronbach's } \\
\text { alpha }\end{array}$ \\
\hline \multirow[t]{2}{*}{ Expected positive impact on the PA profession } & \multirow[t]{2}{*}{11} & 22.08 & \multirow[t]{2}{*}{-.20} & \multirow[t]{2}{*}{-.90} & \multirow[t]{2}{*}{.96} \\
\hline & & $(12.20)$ & & & \\
\hline Expected impact on prerequisites & 5 & $\begin{array}{l}6.53 \\
(3.01)\end{array}$ & -.73 & -.41 & .81 \\
\hline $\begin{array}{l}\text { Expected impact on the student preparedness as PA } \\
\text { faculty and educators }\end{array}$ & 5 & $\begin{array}{l}6.98 \\
(3.12)\end{array}$ & -.94 & -.14 & .84 \\
\hline $\begin{array}{l}\text { Expected impact on the student preparedness as } \\
\text { clinicians }\end{array}$ & 7 & $\begin{array}{l}5.64 \\
(4.95)\end{array}$ & 4.11 & -1.23 & .93 \\
\hline \multirow[t]{2}{*}{ Expected impact on accreditation and certification } & \multirow[t]{2}{*}{3} & 4.59 & \multirow[t]{2}{*}{-1.17} & \multirow[t]{2}{*}{.26} & \multirow[t]{2}{*}{.82} \\
\hline & & $(1.87)$ & & & \\
\hline Expected impact on curriculum & 4 & $\begin{array}{l}24.16 \\
(3.01)\end{array}$ & -.69 & .59 & .63 \\
\hline Expected impact on PA educators & 3 & $\begin{array}{l}9.00 \\
(2.40)\end{array}$ & -.72 & .34 & .67 \\
\hline Expected positive impact on diversity & 5 & $\begin{array}{l}4.05 \\
(3.43)\end{array}$ & .82 & .02 & .82 \\
\hline \multirow[t]{2}{*}{ Expected negative impact on the PA profession } & \multirow[t]{2}{*}{4} & 8.29 & \multirow[t]{2}{*}{-.61} & \multirow[t]{2}{*}{-.13} & \multirow[t]{2}{*}{.51} \\
\hline & & $(2.45)$ & & & \\
\hline Expected impact on the student competency & 6 & $\begin{array}{l}3.53 \\
(2.28)\end{array}$ & -.41 & -1.31 & .86 \\
\hline
\end{tabular}

Figures 


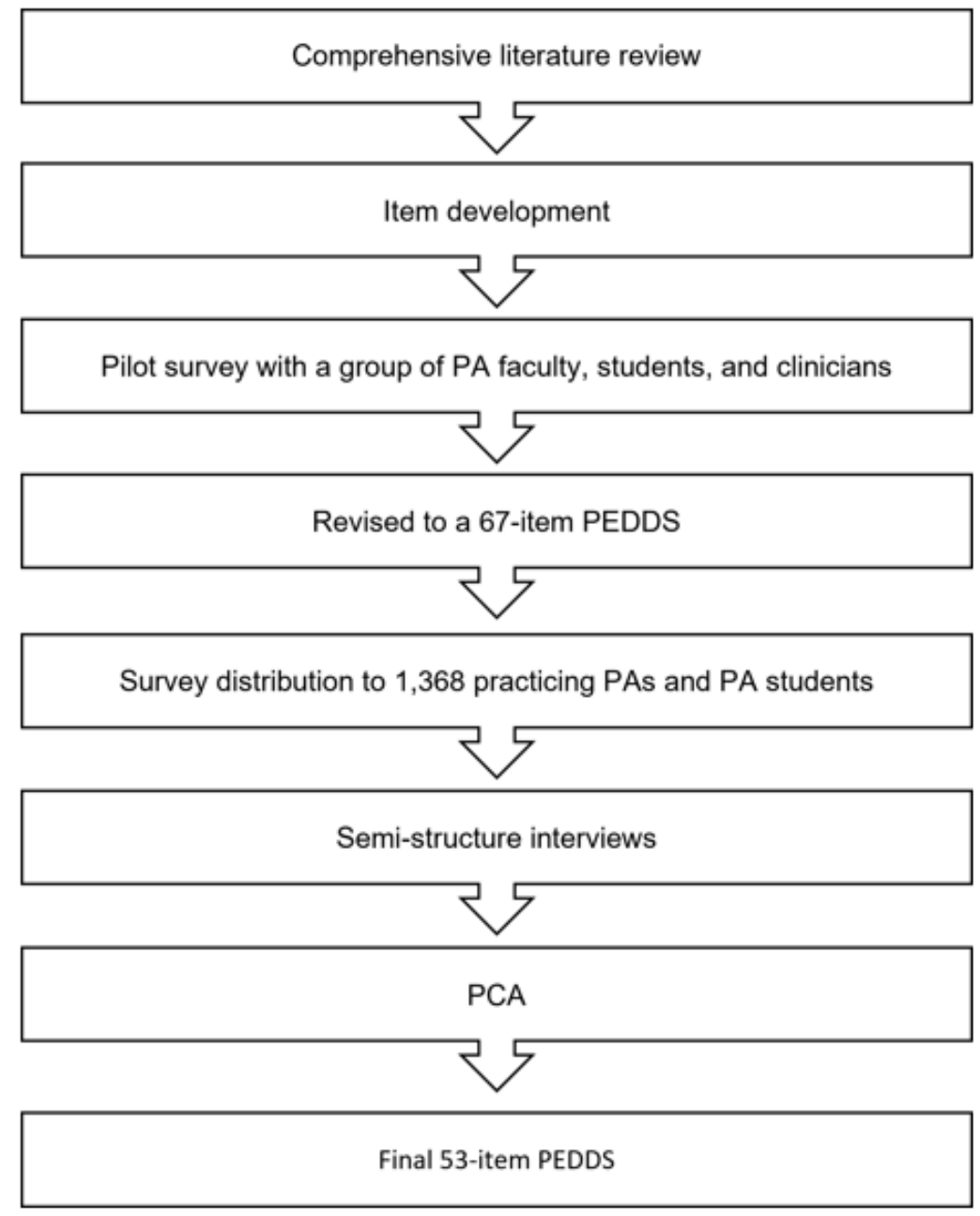

\section{Figure 1}

Scale development methodology

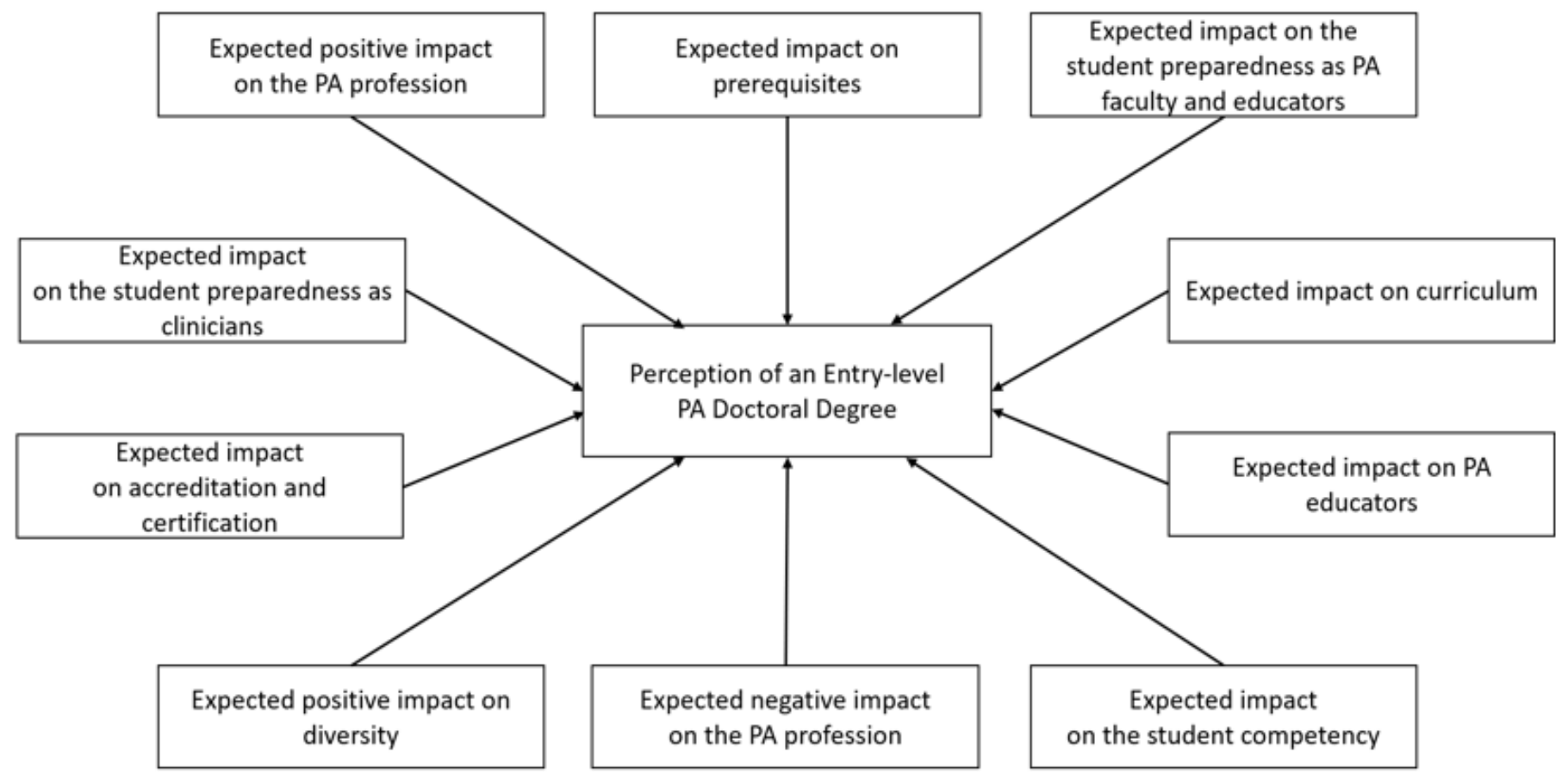


Figure 2

Proposed Model for Perceptions of an Entry-level PA Doctoral Degree 